\title{
ANLCHMPP-91196
}

\section{The Radioactivity of Atmospheric Krypton in 1949-1950a}

Anthony Turkevich, b Lester Winsberg, ${ }^{c}$ Howard Flotow, d Richard M. AdaFise EIVED

Summary

AllG 041997

The chemical element, krypton, whose principal source is the atmosphere, had a long-lived radioactive content, in the mid 1940s, of less than 5 dis. per min. per liter of krypton. In the late 1940s this had risen to values in the range of a hundred dis. per min. per liter. It is now some hundred times higher than the late 1940 values. This radioactivity is the result of the dissolving of nuclear fuel for military and civilian purposes, and the release thereby of the fission product krypton-85 (half-life 10.73 years, fission yield about 0.2 per cent). The present largest emitter of krypton-85 is the French reprocessing plant at Cap-de-la Hague.

\section{INTRODUCTION}

It is generally known that the chemical element, krypton, isolated from the atmosphere in 1996, is radioactive. For example, Wilhelmova et al. (1) quote the air in Prague, Czechoslovakia, as having an average krypton-85 content of $0.8 \mathrm{~Bq}$. per cubic meter of air in the period 1983-1988. This radioactivity is the result of dissolving of nuclear fuel from military and civilian programs of the past and of present civilian power programs.

The largest current producer of radioactive krypton is the French reprocessing plant at Capde-la-Hague, which released 1.8 up $17 \mathrm{~Bq}$. of krypton radioactivity in 1994 (2). If diluted by the whole world's atmosphere, this would produce a radioactivity of krypton of 2400 dis. per min. per liter (STP). Cap-de-la-Hague's output may represent about half of the present input into the atmosphere of this radioactive nuclide.

The present paper provides the earliest known measurements of the krypton radioactivity in the United States, relates them to the output of the Hanford reactors and of the nuclear explosions that had occurred before the samples were collected, and points out the special characteristics of krypton-85 for studying atmospheric mixing on a planetary and subplanetary scale.

DISTRIBUTION OF THIS DOCUMENT IS UNLIMTED 8

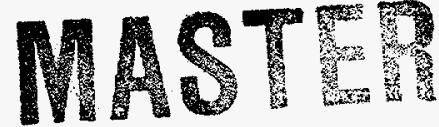


The nuclear fission product, krypton-85, was discovered independently by Thode and Graham in Canada (3), and by Hoagland and Sugarman in the United States (4) in the mid 1940s. It was found to have a half-life of about 10 years (the presently listed value is 10.73 years $(5)$ ), to decay primarily by beta emission (a branch emitting a half $\mathrm{MeV}$ gamma ray was later found (6)), and to be formed in about 0.23 per cent of the thermal neutron induced fissions of uranium-235.

Soon after the war, while writing up the fission product research of the war, Turkevich (7) pointed out the special characteristics of this fission product for, among other uses, tracing air masses on a worldwide scale.

Preliminary measurements made in a screen-wall counter by Libby (8) and Turkevich and Libby (9) gave indications that these predictions were correct. The present report describes the technique that was used soon afterward to establish more precisely that atmospheric krypton in the late 1940s was much more radioactive than it had been, and gives the results of some early measurements of krypton samples isolated from the atmosphere at that time.

\section{MEASUREMENT TECHNIQUE}

The measurement technique that was used was influenced by those simultaneously being developed by Libby and Anderson (10) to measure the radiocarbon content of samples of archeological interest. In contrast to Libby's work, however, Geiger counting of gas samples was employed. The counters, made of brass, were 3 inches in diameter and 24 inches long, with an insulated central wire of 0.5 mil tungsten. The volume of the counters was about 2.3 liters.

The counters, filled with an inert gas, after shaking, had a background counting rate, in an open room, of about 1000 counts per minute. When they were inserted into a "tomb" consisting of a shelf of 8 inches of steel surrounded by 4 inches of lead, the background went down to about 350 counts per minute. A more drastic reduction was achieved by operating the counters not only inside the tomb but also inside a bank of 2-inch Geiger counters that were used in anti-coincidence 
to cancel out cosmic ray events. Only events that were not in coincidence with the shelf counter discharges (1900-2000 per minute) within about 70 microseconds, were accepted.

There was provision for two counters inside this massive shielding and anti-coincidence counters. Use of this technique lowered the background of a counter to 16-35 counts per minute. The residual activity was mostly due to the construction materials of the individual counters. The dead time of the counter was about 5 milliseconds, leading to a correction of less than 4 per cent for the most radioactive samples measured. Typical counting times were 8-12 hours in the work reported here. Assurance of statistical behavior was obtained from a 15-minute printout of the disintegrations recorded during the long measurement times.

It was established that the response of a counter was adequately insensitive to position in the tomb, to the presence of the other counter, or the krypton radioactivity in it. At the time of these measurements a typical sample had a counting rage of 150 counts per minute when filled to a pressure of $20 \mathrm{~cm}$ of $\mathrm{Hg}$. We are indebted to Mr. Tom Brill of the Argonne Electronics Shop for the electronics used in this program.

The work reported here was carried out in the old ruling engine room for grating production in the basement of the Ryerson Physics Laboratory of the University of Chicago.

The counters were filled to a pressure of 100 to 500 tor of the gas to be measured (krypton or argon) and 15 tor of a quench gas. Ethyl alcohol was used for this purpose for most of the measurements; later measurements were made with ethyl ether as quench gas. After filling the counters and shaking with an internal shaker to promote mixing, the applied high voltage was increased until the counting rate indicated a plateau region (less than 10 per cent change in counting rate per 100 volt change in operating voltage. Counters filled with a gas having no radioactivity had larger slopes.) A 2.0 volt output pulse was obtained at a voltage of 2200 volts when the counter was filled with a krypton pressure of 300 tor and 15 tor of a quench gas. The plateau measurements and a monitor of counter behavior were facilitated by use of a capsule of a radium solution that could be placed in a reproducible position near the counter. 
Early measurements, made on three different krypton samples, established that the radioactivity being measured was due to the krypton in the counters. Successive measurements showed that nothing shorter lived or longer lived than the 10.7-year half life was present in detectable amounts.

Special efforts were made to assure the chemical purity of the samples that were measured. These always included adsorption and desorption from activated charcoal under controlled conditions, and removal of reactive components by treating the gas with finely divided calcium prepared by dissolving the calcium in liquid ammonia and then evaporating the ammonia (11). The purified krypton had to show the correct vapor pressure at liquid nitrogen temperature $(1.9+0.2$ tor $)$.

Although the specific origin of the radioactivity that was found in contemporary gas samples could not be pinned down completely, three samples of gas that had been isolated from the atmosphere before 1934 (gases \#3, 5, and 38) showed no radioactivity, whereas all samples isolated from the atmosphere after mid-1947 had easily measurable radioactivity (see below). This makes assignment to nuclear fuel production most probable.

\section{SAMPLE PROCUREMENT}

All the samples measured for this report were procured by Mr. Balcar (12) from operating commercial liquid air plants in northeastern United States. Up until October 1949, the samples represent plant operations lasting several days with perhaps 10 per cent representing a "heel" from earlier days' operations. After that date, the plant operation period was restricted to the day listed, except as noted. However, even here, only about 50 per cent of the krypton produced represented the air processed that day; some 13 per cent came from air that had entered the plant the day before, and so on. Thus, these early samples represent an average over several days of the krypton-85 content of the ambient air. 


\section{SAMPLE MEASUREMENT PROCEDURE}

Each sample was measured at least twice, in different counters or at different pressures. The duration of each measurement was at least 8 hours. The 15-minute records of each measurement were examined to be sure that they were consistent with the totals, exhibited no trends, and that the fluctuations were compatible with statistics. The number of events that had been canceled by the anti-coincidence counters was noted and had to be within a small range. The results from the two measurements, after background subtraction, had to agree within the statistical accuracy of the measurements before the results were accepted. Occasionally, a third measurement, sometimes after gas purification, was required.

The routine activity measurements of a gas were made relative to the activity of a "standard gas" (gas \#21, collected at Philadelphia, PA, between $4 / 26$ and 5/10,1949). This was done by measuring the standard gas in the counter involved. Typically, some 10-20 routine gas measurements were made between standard gas measurements. The standard gas had an activity of about 200 dis. per min. at STP on its collection date.

Similarly, the background of a particular counter was determined, usually at the time of standard gas measurements, by a measurement of the activity of pre-nuclear age krypton (see below). The measurement of the standard gas and of the background of a counter represented a "calibration" of the counter.

\section{ABSOLUTE RADIOACTIVITY}

Thus, the routine gas measurements provided the activity of the gas in question relative to the activity of the standard gas. The absolute activity of the standard gas was determined in two different ways: In the first, a sample of this gas was given to Mrs. A. Engelkemeier, of the Argonne National Laboratory, who was collaborating with Dr. W. F. Libby at the time, and using a screen-wall counter (13). She added a known amount of radioactive krypton to the gas. From the decrease in radioactivity, the activity of the standard gas could be determined. 
In the second method, two counters were constructed in this laboratory, identical in diameter and in other construction details, but of two different lengths. The lack of efficiency at the walls of these large counters was estimated to be small (about 0.6 per cent), and the difference in counting rate per unit volume could be assigned to the inefficiencies of the counters at the ends. The two methods agreed, with the method using counters of different lengths having a smaller error. The effective volume of a typical counter was thus determined to be 98.0 per cent of the value calculated from the length of the bare central wire (the effective volume of one of the counters was 2.43 ( +2 per cent) liter). In this way it was determined that the standard gas had a disintegration rate of 191 dis. per min. per liter (standard conditions) on the collection date. This corresponds to anisotopic abundance of 5.5 down 14 of krypton-85 in the standard gas on collection date.

All routine gas measurements were corrected to the time that the particular gas was collected (separated from the ambient atmosphere) and were then converted to absolute values using this value for the activity of the standard gas. The corrections for decay between collection time and measurement time were usually less than 4 per cent for the samples discussed here.

The statistics of counting of the duplicate measurements of the routine gas samples were well below 1 per cent. The agreement of the duplicate measurements suggest that the radioactive assays carry a one sigma uncertainty of 3 per cent, with most of this coming from the manipulation of the gas samples.

\section{RADIOACTIVITY OF PRENUCLEAR AGE KRYPTON}

At the time that this program was initiated, it was important to establish a limit to the radioactivity of prenuclear-age krypton. This was done in the following way: Three samples of krypton were obtained (12) that had been isolated from the atmosphere before 1945: gas \#3, prepared in July 1932; gas \#5, prepared before 1934; and gas \#38, old, but date of isolation uncertain. They were measured in our counters at several pressures. A sample of argon was measured in the same counter, as well as a sample of gas collected after 1945 (gas \#18, collected in Buffalo, NY, 
during July 1948). The results of one of the comparisons are presented in Figure 1. Shown in the figure are the counting rates of the three gases (prenuclear age krypton, argon, and krypton collected in 1948) as a function of pressure. The figure indicates that the counting rate with prenuclear age krypton (isolated from the atmosphere before 1945) was very nearly the same as that when argon was in the counter, and that the counting rate of these two gases did not increase with pressure. In contrast, the counting rate when the krypton collected in 1948 was in the counter was much higher, and increased linearly with the pressure of the filling. The extrapolated value of the radioactivity at zero pressure of gas \#18 is indistinguishable from that of argon and prenuclear age krypton.

The calculated limit on the radioactivity of prenuclear age krypton (from the lack of increase of the counting rate with pressure) is 5 dis. per mi. per liter (STP) of krypton. The other two pre1945 gases behaved similarly.

The only value available to compare with this number is the estimate of Sytra and Butke (14). They have calculated that the cosmic-ray production of krypton- 85 by neutrons in the atmosphere is 5.2 up $13 \mathrm{~Bq}$. per year. This would lead to an activity of about 10 dis. per min. per liter of krypton. This estimate is in adequate agreement with our upper limit.

Several samples of gases collected after 1945 were measured several times, often after extensive purification. They showed no change in specific radioactivity, nor any decay than what could be attributed to krypton-85. Finally, one sample was analyzed mass spectrometrically, after radiochemical assay, and found to have, at most, 0.5 per cent of xenon.

As mentioned earlier, atmospheric krypton in the 1990s has a radioactivity of tens of thousands of dis. per min. per liter. It is now about a hundred times more radioactive than the samples reported on here.

\section{ATMOSPHERIC MEASUREMENTS AND INTERPRETATIONS}

Many samples were collected and measured during the period covered by this report. The results of krypton radioactivity assays made on some of these are presented in Table I. All results 
presented here were on samples collected at commercial liquid-air plants, with varying control of operating characteristics. Some of these conditions are mentioned below.

The first Soviet explosion of a nuclear device occurred in August 1949. The data reported here on samples collected before about this date have been analyzed on the assumption that the only significant emitter of krypton- 85 affecting them was the Hanford, Washington, reprocessing plant of the United Sates and the nuclear tests carried out by this country. The yearly and monthly emissions of the Hanford plant have been published $(15,16)$. The latter document (16) gives the monthly dissolvings in terms of Mega-watt days of neutron exposure of the fuel that was dissolved. These have been converted to curies of krypton- 85 released in a way to be consistent with the data of (15).

A detailed comparison of the amount of krypton- 85 in the whole world's atmosphere and the measurements reported here will not be made, because it depends on specific meteorological situations near the emitter and collector at the sampling date. Some general remarks will be made.

Table I presents measurements made on krypton isolated from the atmosphere at several locations in northeastern United States before mid-1950. For each location, the first column identifies the gas. The second gives the dates of operation of the liquid-air plant involved. The third column gives the result of the measurement of the specific activity of the isolated krypton, in dis. per min. per liter (STP). The last column gives, for dates before about August 10, 1949, the expected specific activity of krypton if the Hanford output were diluted by the whole world's atmospheric inventory of krypton, taken here as 4.506 up 15 liters (STP). The collection dates listed should be considered with the following points in mind: The dates correspond to plant operating dates when the krypton was removed from a commercial liquid-air plant. If a range of dates is given, it indicates that the air sampled came from at least this period. Even if only one date is indicated, it probably still involves the processing of air from several days, about half of the krypton coming from the air of the date listed, the rest coming from previous days' operations. The output from Hanford was calculated on the assumption that the numbers given in (16) were emitted evenly through the year. 
Although detailed analysis of the data presented here would involve specific meteorological information about conditions on the days involved, some general remarks can be made:

1. The absolute amounts of radioactivity observed are, in all cases, significantly higher than would be expected from instantaneous mixing with the whole world's atmosphere. For example, the four samples taken on August 4, 1949, at different locations in northeastern United States, measure 163, 188, 203, and 199 dis. per min. per liter (STP). They were each measured five times. The Hanford output as of this day, diluted by the world's krypton, would lead to an activity of 115 in the same units. The few per cent contribution of nuclear explosions have been included. This discrepancy is not surprising in view of the faster production of krypton- 85 by the U.S. military program than the decay of this nuclide in the atmosphere. Because the plutonium production plants were in the northern hemisphere, and the mixing with the southern hemisphere takes time (see e.g., 17,18), it is to be expected that the average northern hemisphere values would be higher than worldwide averages.

2. The ratio of observed specific activities to those expected from infinitely fast diffusion seems to take an abrupt rise at the end of 1949. This may be due to meteorological conditions-faster flow from Hanford to the sampling sites, and less vertical mixing on the way. However, an accelerated Seviet reprocessing schedule during those early days of their program, cannot be excluded from contributing.

3. Even though the sampling times cannot be defined to as little as one day, the variability observed, for example, in the August 4, 1949 samples, is greater than the experimental errors (these particular samples were each measured five times). Similarly, the time sequence of the measured specific activities at a given location indicates a larger scatter than can be explained from the experimental errors. This suggests that the northeastern U.S. sampling sites are randomly situated relative to a meandering plume from Hanford, Washington.

In any case, these observations of the krypton- 85 content of the early nuclear-age atmosphere provide data on the rate of large-scale mixing of the components of the world's atmosphere. They provide quantitative data on how activities in one part of the globe affect the rest of the world. 


\section{ACKNOWLEDGMENTS}

Many people contributed to the work reported here. Even at this late date it is easy to remember the support provided by S. G. English, of the U. S. Atomic Energy Commission, Tom Brill of the Argonne National Laboratory, and W. F. Libby of the University of Chicago. B. R. Balcar, special consultant to the project, provided the samples. L. Machta of the U. S. Weather Bureau provided meteorological support. Unfortunately, not much of this shows in this report. Finally, W. Nicholson of Batelle Northwest, in addition to his statistical analyses, located records of early Hanford operations.

\section{REFERENCES AND NOTES}

(a) This paper is based, in large part, on reports ANL-4360 (Oct. 20, 1949, L. Winsberg and A. Turkevich) and ANL-HDY-694 (Aug. 10, 1951, L. Winsberg, H. Flotow, A. Turkevich, and R. M. Adams).

(b) Present address: Anthony Turkevich, Enrico Fermi Institute, University of Chicago, 5640 S. Ellis Ave., Chicago, IL 60637.

(c) Deceased

(d) Present address: Howard Flotow, 121 Mariner Drive, Tarpon Springs, FL 34689.

(e) Present address: R. M. Adams, 3901 Grays Gable Road, Laramie, WI 82070.

1. L. Wihelmova, H. Tomasek, and K. Stukheit, J. Radionucl. Nucl Chim Lett. 144, 125 (1990).

2. J. Pellissier-Taanov, private comm. to L. Machta. Presented to the World Meteorological Congress, Vienna, Austria, 1995.

3. H. G. Thode and R. L. Graham, Can J. Res. 25A, 1 (1947). Based on Report MA-129, 1945, April.

4. E. S. Hoagland and N. Sugarman, paper \#69, Radiochemical Studies: The Fission Products, C. D. Coryell and N. Sugarman, eds., Book 2, Part V., McGraw-Hill (1951).

5. C. M. Lederer et al., Table of Isotopes, 7th Edition, Wiley and Sons, New York, 1978. 
6. H. Zeldes, B. H. Ketelle, and A. R. Brosi, Phys. Rev. 79, 901 (1950).

7. Letter from A. Turkevich to P. Morrison with copies to N. Bradbury (LANL) and W. Zinn (ANL, July 19, 1946 (ANL-NS-6)).

8. W. F. Libby, Unpublished measurements in screen-wall counter (1947).

9. A. Turkevich and W. F. Libby, Unpublished measurements in Libby's screen-wall counter (1948).

10. E. C. Anderson, Ph.D. Thesis with W. F. Libby, University of Chicago (1949).

11. W. C. Johnson. M. F. Stubler, H. F. Sidwell, and L. A. Pechukar, J. Am. Chem. Soc. 61, 321 (1939).

12. B. R. Balcar, Special Consultant to U. S. Government Agencies. We are indebted to Mr. Balcar for these samples and for data on the collection times.

13. A. Engelkemeier, Chemistry Division, Argonne National Laboratory, Argonne, IL 60439 .

14. Styra and Butku, Geophysical Problems of $K r-85$ in the Atmosphere, Washington, D.C., 1991.

15. Letter from R. L. Stutheit to A. A. Sinisgalli, 1994, Oct. 19.

16. C. M. Heeb, Radioactive Releases into the Atmosphere, PNWD-2222 HEDR., 1994, May.

17. H. B. Singh, Science, 203, 899 (1979).

18. R. G. Prinn et al., Science 269, 187 (1995). 
Table I. Radioactivity of Atmospheric Krypton Before Mid 1950. All activity is in dis. per min. per liter (STP).

\begin{tabular}{|c|c|c|c|}
\hline Gas \# & Collection date & $\begin{array}{c}\text { Observed } \\
\text { activity }\end{array}$ & $\begin{array}{l}\text { Activity due to } \\
\text { U. S. operations }\end{array}$ \\
\hline \multicolumn{4}{|c|}{ Philadelphia, PA } \\
\hline 21 & $4 / 28 / 49-5 / 10 / 49$ & 191 & 110 \\
\hline 33 & $8 / 4 / 49$ & 163 & 118 \\
\hline \multicolumn{4}{|c|}{ Johnstown, PA } \\
\hline 7 & $<9 / 1 / 47^{*}$ & 101 & 70 \\
\hline 22 & $1 / 1 / 49-1 / 7 / 49$ & 198 & 100 \\
\hline 25 & $1 / 1 / 49-1 / 7 / 49$ & 198 & 100 \\
\hline 26 & $3 / 12 / 49-3 / 14 / 49$ & 166 & 109 \\
\hline 53 & $7 / 25-7 / 28 / 49$ & 156 & 115 \\
\hline 31 & $8 / 4 / 49$ & 188 & 115 \\
\hline 73 & $1 / 29 / 50$ & 304 & \\
\hline 74 & $1 / 31 / 50$ & 264 & \\
\hline 75 & $2 / 16 / 50$ & 331 & \\
\hline 76 & $2 / 18 / 50$ & 325 & \\
\hline 77 & $2 / 20 / 50$ & 307 & \\
\hline 78 & $2 / 21 / 50$ & 296 & \\
\hline 79 & $2 / 23 / 50$ & 266 & \\
\hline 80 & $2 / 25 / 50$ & 296 & \\
\hline 82 & $3 / 6 / 50$ & 272 & \\
\hline 83 & $3 / 13 / 50$ & 250 & \\
\hline 84 & $3 / 23 / 50$ & 260 & \\
\hline 85 & $3 / 30 / 50$ & 278 & \\
\hline 89 & $4 / 7 / 50$ & 268 & \\
\hline 91 & $4 / 19 / 50$ & 240 & \\
\hline 92 & $* * 4 / 27 / 50$ & 300 & \\
\hline 132 & $5 / 28 / 50$ & 277 & \\
\hline 133 & $6 / 3 / 50$ & 269 & \\
\hline 151 & $6 / 30 / 50$ & 295 & \\
\hline \multicolumn{4}{|c|}{$\begin{array}{l}* \text { Probably the first } 6 \text { months of } 1947 \text {. } \\
* * 0800-2000 / 4 / 27 / 50\end{array}$} \\
\hline \multicolumn{4}{|c|}{ Pittsburgh, PA } \\
\hline 35 & $1 / 28 / 49$ & 173 & 102 \\
\hline 60 & $5 / 12 / 49$ & 171 & 111 \\
\hline 61 & $5 / 16 / 49$ & 171 & 113 \\
\hline 28 & $6 / 28-29 / 49$ & 177 & 113 \\
\hline 36 & $7 / 24 / 49$ & 184 & 115 \\
\hline 37 & $8 / 11-13 / 49$ & 195 & \\
\hline 54 & $8 / 20-26 / 49$ & 176 & \\
\hline 55 & $9 / 13-17 / 49$ & 212 & \\
\hline 56 & $9 / 25-28 / 49$ & 189 & \\
\hline 62 & $10 / 19 / 49$ & 211 & \\
\hline 57 & $10 / 28-29 / 49$ & 194 & \\
\hline
\end{tabular}




$$
\begin{aligned}
& 58 \\
& 59 \\
& 63 \\
& 64 \\
& 65 \\
& 66 \\
& 68 \\
& 69 \\
& 70 \\
& 67 \\
& 71 \\
& 72 \\
& 90
\end{aligned}
$$

Boston, MA

20

27

29

32

41

42

43

44

45

46

47

49

50

51

52

108

*Only one measurement possible
197

236

232

335

227

261

302

237

227

308

250

264

253

138

160

152

203

$165 *$

177

161

164

164

164

167

165

159

163

197

248
94

113

113

115

Buffalo, NY

17

18

19

34

$5 / 1-5 / 1 / 57$
$7 / 11-7 / 25 / 48$
$12 / 10 / 48-1 / 13 / 49$
$8 / 4 / 49$

103

97

202

199
63

89

99

115 


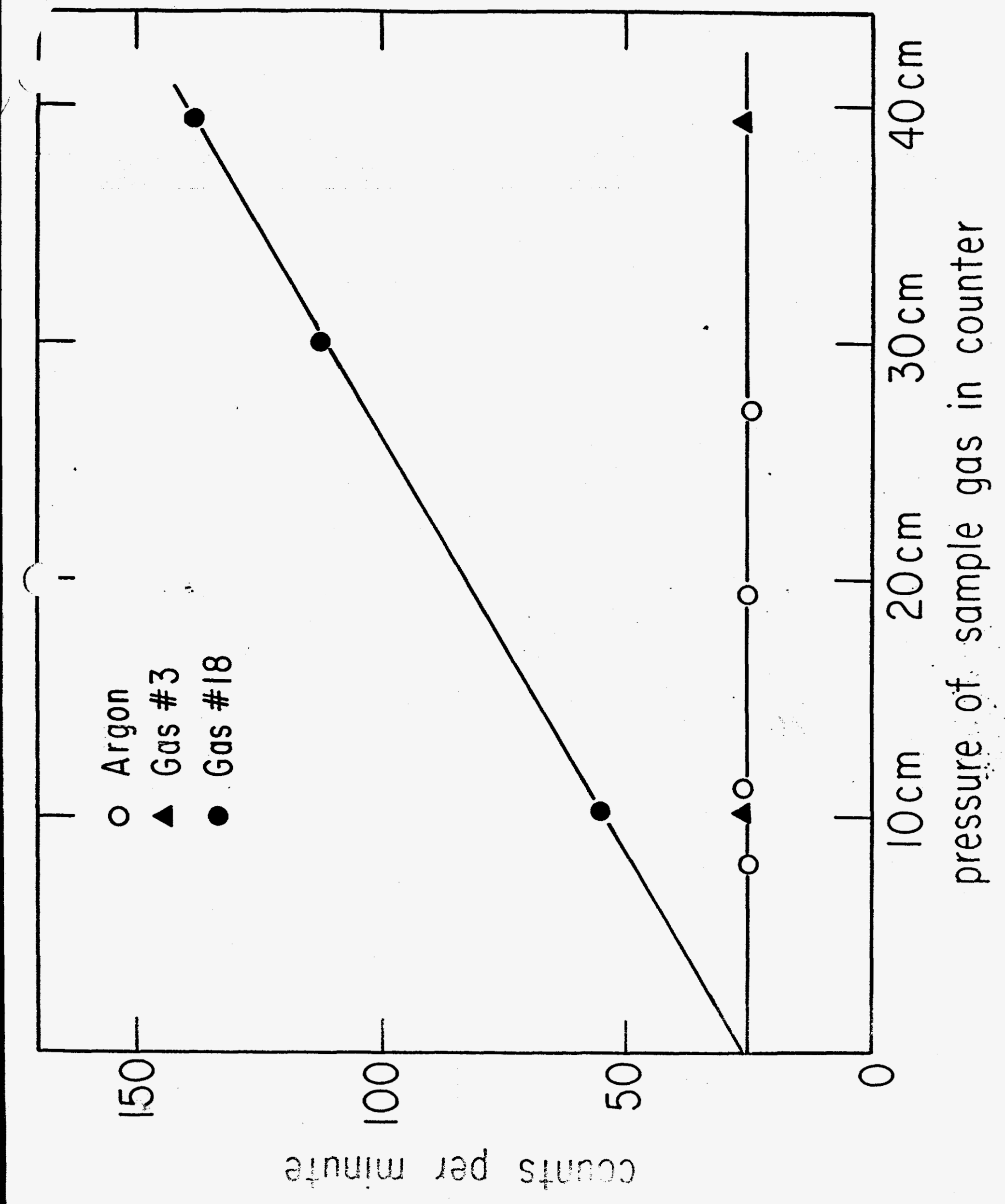




\section{DISCLAIMER}

This report was prepared as an account of work sponsored by an agency of the United States Government. Neither the United States Government nor any agency thereof, nor any of their employees, makes any warranty, express or implied, or assumes any legal liability or responsibility for the accuracy, completeness, or usefulness of any information, apparatus, product, or process disclosed, or represents that its use would not infringe privately owned rights. Reference herein to any specific commercial product, process, or service by trade name, trademark, manufacturer, or otherwise does not necessarily constitute or imply its endorsement, recommendation, or favoring by the United States Government or any agency thereof. The views and opinions of authors expressed herein do not necessarily state or reflect those of the United States Government or any agency thereof. 


\section{DISCLAMMER}

Portions of this document may be illegible in electronic image products. Images are produced from the best available original document. 